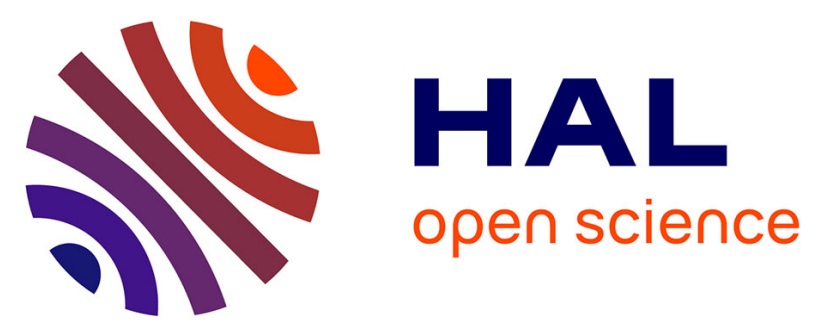

\title{
Silane/TiO 2 coating to control the corrosion rate of magnesium alloys in simulated body fluid
}

\author{
L.C. Córdoba, M.F. Montemor, Thibaud Coradin
}

\section{To cite this version:}

L.C. Córdoba, M.F. Montemor, Thibaud Coradin. Silane/TiO 2 coating to control the corrosion rate of magnesium alloys in simulated body fluid. Corrosion Science, 2016, 104, pp.152-161. 10.1016/j.corsci.2015.12.006 . hal-01243699

\section{HAL Id: hal-01243699 \\ https://hal.sorbonne-universite.fr/hal-01243699}

Submitted on 15 Dec 2015

HAL is a multi-disciplinary open access archive for the deposit and dissemination of scientific research documents, whether they are published or not. The documents may come from teaching and research institutions in France or abroad, or from public or private research centers.
L'archive ouverte pluridisciplinaire HAL, est destinée au dépôt et à la diffusion de documents scientifiques de niveau recherche, publiés ou non, émanant des établissements d'enseignement et de recherche français ou étrangers, des laboratoires publics ou privés. 


\section{Silane/ $\mathrm{TiO}_{2}$ coating to control the corrosion rate of magnesium alloys in simulated body fluid}

L.C. Córdoba ${ }^{\mathrm{a}, b^{*}}$, M.F. Montemor ${ }^{\mathrm{a}}$, T. Coradin ${ }^{\mathrm{b}}$

${ }^{a}$ CQE, Instituto Superior Técnico, Universidade de Lisboa, Av. Rovisco Pais, 1049-001

Lisboa, Portugal

${ }^{b}$ Sorbonne Universités, UPMC Univ Paris 06, CNRS, Collège de France, Laboratoire de

Chimie de la Matière Condensée de Paris, 11 place Marcelin Berthelot, 75005 Paris, France

*Corresponding author: lauracordoba@tecnico.ulisboa.pt, Phone: (+351) 218417962, Fax: (+351) 218417991

Postal address: Instituto Superior Técnico, Lab. de tecnologia electroquímica, Pavilhão de Minas, Piso 4, Av. Rovisco Pais 1049-001 LISBOA

M.F. Montemor: mfmontemor@tecnico.ulisboa.pt

T. Coradin: thibaud.coradin@upmc.fr 


\section{Highlights}

- A well-developed silane/ $\mathrm{TiO}_{2}$ coating controlled corrosion rate of two $\mathrm{Mg}$ alloys.

- The protective ability of the coating depends upon the nature of the alloy.

- $\mathrm{A} \mathrm{Mg}(\mathrm{OH})_{2}$ and $\mathrm{Ca} / \mathrm{PO}_{4}$ containing layer of corrosion products was found.

- The coating favors the formation of a non-stoichiometric hydroxyapatiterich layer. 


\section{Abstract}

A silane-based coating modified with titanium IV iso-propoxide was developed to slow down the corrosion rate of AZ31 and ZE41 magnesium alloys intended as biodegradable implants materials. Electrochemical impedance spectroscopy (EIS) was used to monitor the corrosion evolution over 7 weeks in simulated body fluid at $37^{\circ} \mathrm{C}$. A homogeneous crack-free $3 \mu \mathrm{m}$-thick coating provided corrosion protection for 2 and 3 weeks to the ZE41 and the AZ31, respectively.

The corrosion mechanisms and the nature of the corrosion products of the coated systems are discussed and correlated to the coating morphology before and after the immersion tests.

Keywords: A. Magnesium; A. Alloy; B. EIS; C. Polymeric coatings; C. Alkaline corrosion. 


\section{Introduction}

Magnesium (Mg), and particularly its alloys, have drawn interest as biodegradable materials over the last years [1-4]. Compared to other biomaterials, $\mathrm{Mg}$ alloys present a considerable number of advantages: (i) high strength-to-weight ratio makes them suitable for load-bearing applications; (ii) their elastic modulus ( $43 \mathrm{GPa})$ is close to that of bone minimizing stress shielding effect; (iii) $\mathrm{Mg}$ is present in large amount in the human body and it is essential for several metabolic processes [5-10]. However, the corrosion resistance of $\mathrm{Mg}$ alloys is poor and they undergo a rapid dissolution in simulated physiological media [11]. Indeed, this behaviour makes them unsuitable for fabrication of permanent implants such as endoprosthesis or hip replacement devices. However, it is possible to take advantage of their rapid biodegradation to design temporary implants. Particularly in bone repair therapy, $\mathrm{Mg}$ alloys have shown to be beneficial for bone growth and strengthening [12].

The rapid intrinsic degradation of $\mathrm{Mg}$ alloys in chloride-containing solutions, including human blood plasma [13], has hindered their widespread clinical application so far. In addition to the unfavourable corrosion kinetics of $\mathrm{Mg}$, the accompanying hydrogen evolution $\left(\mathrm{H}_{e v o}\right)$ is a major issue. Hydrogen gas pockets adjacent to the implant can be formed causing structural disorders of the surrounding tissues and delay the healing process [14]. In addition, $\mathrm{H}_{\text {evo }}$ leads to local increase of the $\mathrm{pH}$ that might induce toxicity events [15]. Surface coating have shown to be a promising strategy to slow down the corrosion rate of $\mathrm{Mg}$ alloys and modulate it to levels at which detrimental effects are negligible [4]. Considering that these coatings must interact in a favourable manner with bone cells, many of the current approaches incorporate hydroxyapatite particles resulting in hybrid/composite layers [15-17]. Alternative options rely on the deposition of bioactive layers that favour hydroxyapatite precipitation from simulated body fluids (SBFs) $[18,19]$. Those containing $\mathrm{TiO}_{2}$, a recognized biocompatible oxide, have high potential for surface functionalization of $\mathrm{Mg}$ alloys [20].

In the present study we propose a silane-based coating formulation, modified with titanium iso-propoxide to slow down and to control the corrosion rate of $\mathrm{Mg}$ alloys intended as biodegradable implants. The study was performed using electrochemical impedance spectroscopy in simulated body fluid (SBF) at physiological temperature. Depending upon the alloy system, the corrosion mechanisms are discussed. 


\section{Experimental procedures}

\subsection{Materials and substrate preparation}

Extruded rods of AZ31 and ZE41 alloys (ASTM designation) with the chemical composition indicated in Table 1 (as detailed by the manufacturer Magnesium Elektron Company) were used in the present study. Discs of diameter $25 \mathrm{~mm}$ and 3mm-thick were grinded sequentially with 180,400 , and $1000 \mathrm{SiC}$ grit papers and pre-treated with $12 \% \mathrm{HF}$ solution by immersion for 15 minutes to promote the formation of a $\mathrm{MgF}_{2}$ surface layer [21]. All discs were rinsed with ethanol (96\%, Sigma-Aldrich) and dried in air stream as final step.

\subsection{Synthesis of the sol-gel coating and thermal conditioning}

The coating formulation was selected based on previous investigations [22] and optimized for the purpose of this work. Two different alkolsols were mixed to obtain the final hybrid coating using the sol-gel route. The first alkolsol was prepared in the presence of acetylacetone (Acac, analytical standard) by the hydrolysis of $70 \%$ titanium (IV) isopropoxide ( $\geq 97 \%$ TIP, Aldrich) in iso-propanol. Diluted aqueous solution of $\mathrm{HNO}_{3}(\mathrm{pH} 0.5$ ) was added resulting in a final volume ratio TIP:Acac: $\mathrm{H}_{2} \mathrm{O}$ of 5:3:1. The second silane-based alkolsol was obtained by the acidic hydrolysis ( $\mathrm{pH} 0.5$ ) of (3-glycidoxypropyl)trimethoxysilane ( $\geq 98 \%$ GPTMS, Aldrich) in iso-propanol and stirred for $1 \mathrm{~h}$ at room temperature. The final volume ratio of GPTMS:2-propanol: $\mathrm{H}_{2} \mathrm{O}$ was 8:8:1. Finally, the titanium-containing and the silane-based alkolsols were mixed together in a volume ratio of 1:1.5, respectively. The combined solution was aged at room temperature for 1 hour and deposited onto AZ31 and ZE41 pre-treated discs by the dip-coating technique. The dipping parameters were 3 immersions of 10 seconds each at a withdrawal speed of $17 \mathrm{~cm} / \mathrm{min}$. The final step after dip-coating procedure was to dry the samples at $120^{\circ} \mathrm{C}$ for 90 minutes in air. Four conditions were tested: $12 \%$ HF pre-treated discs of the alloys designed as (i) AZ31 and (ii) ZE41; (iii) coated AZ31 alloy (AZ31_S) and (iv) coated ZE41 alloy (ZE41_S).

\subsection{Morphological characterization}

or examining the morphology and chemical composition of the coating, field emission gun scanning electron microscope (FEG-SEM) JEOL-JSM7001F equipped with an energy dispersive spectroscopy (EDS) microanalysis was used. All the samples were coated with $\mathrm{Au}$ using a sputter coater system and examined before and after the immersion tests. Additionally, a diffracted backscattered electron detector (EBSD) appended to the SEM was used to assess crystallinity of the coating. 
To determine the film thickness cross-sections were prepared by embedding the sample into an epoxy resin (Buehler) mould at room temperature and grinded up to $2500 \mathrm{SiC}$ grit paper in ethanol.

A Nanosurf Easyscan 2 atomic force microscope (AFM) apparatus was used to determine the coating roughness and to obtain additional morphological information. Unfiltered images of topography, vibration amplitude and phase contrast were obtained in non-contact mode (tapping) at different positions and magnifications on the surface at room temperature using silicon probes.

\subsection{Electrochemical techniques and corrosion products characterization}

Electrochemical impedance spectroscopy (EIS) measurements were carried out in order to characterize the corrosion performance of the coated alloys. The study was performed in naturally aerated simulated body fluid (SBF) pH 7.4 at $37 \pm 1{ }^{\circ} \mathrm{C}$ for 7 weeks. The spectra were recorded at different immersion times using a Gamry Ref. 600 potentiostat at open circuit potential in the $10^{5} \mathrm{~Hz}$ down to $10^{-1} \mathrm{~Hz}$ frequency range. The SBF was prepared following the procedure described in [23] with the composition listed in the Table 2.

A conventional three-electrode electrochemical cell was used, consisting in the sample as working electrode with an exposed area of $3.1 \mathrm{~cm}^{2}$, a saturated calomel electrode (SCE) as reference and platinum coil as counter electrode. All the experiments were performed in a Faraday cage to avoid electromagnetic interferences. The fitting parameters were obtained by analysing the results with ZView3® software.

$\mathrm{X}$-ray diffraction analyses of untested and tested discs were performed using $\mathrm{Cu} \mathrm{K}_{\alpha}$ radiation in a Bruker D8 ADVANCE diffractometer operating at 40kV and 30mA. Raman spectra were acquired in a LabRAM HR800 Evolution Horiba, with a solid-state laser source operating at $532 \mathrm{~nm}$ with a $180^{\circ}$ backscattered geometry, 600 lines/mm grating spectrograph and laser beam power of $20 \mathrm{~mW}$.

\section{Results}

\subsection{Surface morphology of uncoated and as-prepared coated alloys}

The grinded discs were pre-treated for 15 minutes in $12 \%$ HF solution before coating. Fig. 1a and 1b depict the topographic AFM images of the layer formed on the pre-treated discs. Previous studies $[2,24]$ reported that acid treatment with hydrofluoric acid provides a $\mathrm{MgF}_{2}$ layer on $\mathrm{Mg}$ alloys, decreasing corrosion rate in SBF solution [24]. The surfaces of the pre-treated alloys reveal $\mathrm{MgF}_{2}$ crystal strings following the surface roughness (Fig. 1a-1b). 
The morphology of the layer formed on AZ31 showed more compact structure when compared to the layer on ZE41, filling the cleavages between grinded scratches.

Fig. 1c and 1d depict AFM and SEM images of the coating, respectively. Irregularshaped aggregates ranging from $1-10 \mu \mathrm{m}$ in diameter were found on the as-deposited coating. Their distribution over the surface was random with some crowded areas (Fig. 1c). EDX analysis of the aggregates (Fig. 1d) revealed that they consisted of Si and Ti oxides, most likely undissolved particles during the sol-gel preparation step. Topographical AFM images confirmed a smooth and rather homogeneous coating surface of small roughness $R_{q} 21.9 \pm 2.1$ $\mathrm{nm}$ apart from the agglomerates. SEM images showed that the coating did not present relevant defects, such as micro-cracks or micro-pores. Additional analysis by electron backscattered diffraction (EBSD) did not reveal the Kikuchi patterns, suggesting that the coating and the aggregates had predominantly an amorphous structure. This is in accordance to the irregular shape of the agglomerates. The coating showed a homogeneous thickness of $\sim 3.2 \pm 0.4 \mu \mathrm{m}$ irrespectively of the alloy (Fig. 1e).

\subsection{Electrochemical monitoring of the corrosion evolution}

Following the characterization of the coated alloys, the corrosion behavior was studied by EIS at open circuit potential. The measurements were performed by immersing the samples in SBF $(7.4 \mathrm{pH})$ solution at $37 \pm 1^{\circ} \mathrm{C}$. Fig. 2 shows the open circuit potential (OCP) evolution of pre-treated and coated alloys. The OCPs of the pre-treated discs increased to more positive values during first 3 days and remained constant about $-1.52 \mathrm{~V}$ until 2 weeks. Then, the OCPs showed minor fluctuations around this value remaining nearly constant until week $7^{\text {th }}$. The initial rise in OCP can be related to the formation of a layer of corrosion products with protective barrier properties.

The presence of the coating shifts the initial OCPs toward more positive values compared to the uncoated alloys. The OCP of AZ31_S increased slowly during first 3 days whereas that OCP of ZE41_S decreased. After 3 days, OCP of AZ31_S slowly decreased due to degradation of the coating barrier properties. On the other hand, the OCP of ZE41_S stabilized after 3 days followed by a small increase until week $3^{\text {th }}$. Then, the OCP showed a temporary increase to $-1.46 \mathrm{~V}$ around 4 weeks. This feature was also reflected on the EIS results and will be discussed below along with characterization of the corrosion products.

Representative Bode plots obtained for the HF pre-treated alloys (AZ31 and ZE41) and the coated alloys (AZ31_S and ZE41_S) are depicted in Fig. 3 and Fig. 4, respectively. The low frequency impedance values of coated alloys at early immersion were two orders of 
magnitude higher compared to the pre-treated samples, evidencing that the coating provides an effective barrier effect.

The initial low frequency impedance values of the coated alloys were similar, around 6 $\mathrm{x} 10^{4} \Omega \cdot \mathrm{cm}^{2}$ (see Fig. 4). However, with time relevant changes were observed. First, low frequency $\left(10^{-1} \mathrm{~Hz}\right)$ impedance of AZ31_S showed minor fluctuations during first 72 hours. Next, impedance decreased being one order of magnitude lower around week $4^{\text {th }}$. At the same time, the high frequency time constant $\left(10^{3}-10^{5} \mathrm{~Hz}\right)$ gradually vanished due to deterioration of the coating barrier properties.

In the case of ZE41_S, impedance dropped during first 72 hours to a value almost one order of magnitude lower compared to AZ31_S at the same immersion time. However, impedance of ZE41_S revealed a significant increase at later stages. From $2^{\text {nd }}$ to $4^{\text {th }}$ week of immersion the low frequency impedance reached values of $\sim 2 \times 10^{5} \Omega \cdot \mathrm{cm}^{2}$. After this period, the impedance decreased once again to values of $\sim 9 \mathrm{x} 10^{3} \Omega \cdot \mathrm{cm}^{2}$ after week $7^{\text {th }}$. Unlike AZ31_S, the high frequency time constant of ZE41_S was always detected in the spectra during the immersion period. In both coated alloys there were evident signs of corrosion activity. To further detail the nature and morphology of the corrosion products a detailed characterization was carried out.

\subsection{Morphology and composition of the corroded surfaces}

Fig. 5 depicts the surface morphology of uncoated and coated discs after EIS experiments for 7 weeks. The cracks formed on the corrosion products layers, as observed in Fig. 5a-5b, may be due to volumetric contraction during dehydration process after electrolyte removal and the vacuum atmosphere during SEM analysis. Defects as cracks and local delamination evolved in the coating for both AZ31_S and ZE41_S (see Fig. 5c-5d). The arrow in Fig. 5d indicates a delaminated area with flake-like shape. These defects, as well as cracks, were randomly scattered over the entire surfaces. The morphology of the delaminated areas is likely due to local accumulation and growth of corrosion products at the substrate/coating interface as well as to hydrogen evolution $\left(\mathrm{H}_{\text {evo }}\right)$. Visual inspection of the coated samples during immersion revealed the progressive formation of pits. In the ZE41_S discs the first pits appeared after week $1^{\text {st }}$. In the case of AZ31_S, identical pits appeared during week $3^{\text {th }}$.

EDX analysis of the pre-treated samples revealed the elemental composition of the corrosion products layers. The presence of $\mathrm{Mg}, \mathrm{O}, \mathrm{Ca}, \mathrm{P}$ and $\mathrm{C}$ was detected (Table 3). The results evidenced the incorporation of $\mathrm{Ca}, \mathrm{P}$ and $\mathrm{C}$ into the corrosion products. Nevertheless, 
part of the carbon content may come from atmosphere impurities and part from surface deposits too. Calcium and phosphorus come from SBF solution.

To perform EDX analysis on the corrosion products of the coated discs the coating was manually removed. The corrosion layers of AZ31_S and ZE41_S contained higher amount $\mathrm{Mg}, \mathrm{O}, \mathrm{Ca}$ and $\mathrm{Cl}$ elements compared to the pre-treated discs. These results suggest that the local environment created by the presence of the coating along with the corrosion processes may promote the formation of $\mathrm{P}$ and $\mathrm{Ca}$-enriched corrosion products. Additional XRD measurements confirmed that the corrosion layers consisted of $\operatorname{Mg}(\mathrm{OH})_{2}$. Broad diffraction peaks, as observed in Fig. 6a-6b, may suggest poor crystallinity of these layers. In the case of $\mathrm{AZ} 31$ the peaks of $\mathrm{Mg}(\mathrm{OH})_{2}$ were not detected by XRD. There may be two possible explanations of this fact: (i) either the corrosion layer on AZ31 at 7 weeks is amorphous, (ii) or the layer is not thick enough to be detected by XRD. Fig. 7a shows a XRD pattern of pre-treated AZ31 after 1 week of immersion where the peaks corresponding to $\mathrm{Mg}(\mathrm{OH})_{2}$ are clearly observable. This result suggests that crystallinity of the corrosion layers, particularly on AZ31, decreased with the immersion time. In aqueous solutions with high chloride concentrations $\mathrm{Mg}(\mathrm{OH})_{2}$ reacts with $\mathrm{Cl}^{-}$to produce highly soluble $\mathrm{MgCl}_{2}$ [25, 28]. According to this, one hypothesis may be that the former $\mathrm{Mg}(\mathrm{OH})_{2}$ layer might become $\mathrm{MgCl}_{2}$ and dissolve gradually into the solution. In Fig. $3 \mathrm{a}$ and $3 \mathrm{~b}$ it is possible to see that setting-up of the corrosion layers on uncoated discs took place during first 3 days. This is in close agreement with the steep OCP rise for the same period of time as observed in Fig. 2.

Further Raman characterization supported the aforementioned hypothesis. Fig. 7b displays the Raman spectrum of the corrosion layer on AZ31_S and ZE41_S at week $7^{\text {th }}$. The peak at $3648 \mathrm{~cm}^{-1}$ corresponding to the $\mathrm{O}-\mathrm{H}$ fundamental of $\mathrm{Mg}(\mathrm{OH})_{2}$ on the high frequency side was detected on both samples. Since Raman scattering is sensitive to the degree of crystallinity, broader peak and decreased intensity of AZ31_S corrosion layer may indicate lower crystallinity when compared to the corrosion layer of ZE41_S.

Further Raman results confirmed the presence of $\mathrm{Ca}$ and $\mathrm{P}$ in the corrosion layer of both coated discs, as reported in EDX results in Table 3. The corrosion layers consisted then in a mixture of $\mathrm{Mg}(\mathrm{OH})_{2}$ and hydroxyapatite (HAP) for both AZ31_S and ZE41_S. The Fig. 8 depicts Raman spectra of coated discs in comparison to RRUFF ${ }^{\mathrm{TM}}$ patterns [29] of hydroxyapatite (Ref. 060180) and clorapatite (Ref. 060192). It has been reported in previous studies [30] that precipitation kinetics is critical for the purity of HAP and its crystallographic characteristics. Most of the synthetic methods to produce HAP crystals from supersaturated aqueous solutions led to the formation of non-stoichiometric products. This is due to the presence of vacancies and ion substitutes in the crystal lattice such as hydrogen phosphates, 
carbonates, potassium and chlorides, among others [30]. Usually, these species are introduced into the precipitating system with the reactants. Hence, synthetized HAPs incorporating any of the above-mentioned ions undergo significant changes and have different crystal morphology compared to the stoichiometric [30]. This may explain the differences observed in the Raman spectra of AZ31_S and ZE41_S. Correspondingly, the Ca/P molar ratios listed in Table 3 suggest that in the present case the HAPs precipitated from SBF differ from stoichiometric HAP whose Ca/P molar ratio is 1.67. Other authors [27] have also reported that during immersion in SBF, the corrosion of $\mathrm{Mg}$ alloys is accompanied by the formation of corrosion products such as magnesium hydroxide, carbonates and phosphates.

Cross-sectioning of coated samples revealed additional features of the corrosion layers. Fig. 9a shows the cross-section of AZ31_S where a rather thin corrosion layer with a thickness in the range of $4-5 \mu \mathrm{m}$ is observed. Nevertheless, the layer seems to have a dense structure. The local delamination of the coating due to accumulation of corrosion products is also seen in Fig. 9a. This corresponds to the flake-like shaped delaminated areas aforementioned and depicted in Fig. 5c-5d. The occurrence of localized corrosion (pits) was also observed on both AZ31_S and ZE41_S corrosion layers (not shown). The local environment created by the pit formation may promote the pile-up and growth of corrosion products around the pit. Apart from these areas, the thickness of the AZ31_S corrosion layer seemed quite homogeneous.

In the case of ZE41_S, a non-uniform corrosion layer of thickness ranging from 20 to $40 \mu \mathrm{m}$ was observed (Fig. 9b). Large areas where the layer was detached possibly due to further corrosion were also found. Some of these areas reached about $90 \mu \mathrm{m}$ in depth. This may explain the wide OCP variations of ZE41_S as observed in Fig. 2. During first 3 days of immersion the OCP of ZE41_S slightly dropped probably due to deterioration of the coating barrier properties. Next, the OCP stabilized and started rising slowly until week $3^{\text {th }}$. It appeared that the corrosion layer formation took place during this period of time. Then, thickening and densification of the layer could happen from week $3^{\text {th }}$ to week $4^{\text {th }}$. However, the occurrence of pits in the corrosion layer enables the electrolyte to reach the metal surface and further corrosion causes selective detachment of the layer. The proposed corrosion mechanism would explain the OCP drop after 4 weeks of ZE41_S and will be further discussed together with the parameters extracted from the EIS fitting.

\section{Discussion}

\subsection{Corrosion mechanism and modelling}

The most representative redox reactions responsible for the overall corrosion process of $\mathrm{Mg}$ alloys are listed below [22]: 


$\begin{array}{lll}\text { Cathodic reactions } & 2 \mathrm{H}_{2} \mathrm{O}+2 \mathrm{e}^{-} \rightarrow 2 \mathrm{OH}^{-}+\mathrm{H}_{2} \uparrow \\ & \mathrm{O}_{2}+2 \mathrm{H}_{2} \mathrm{O}+4 \mathrm{e}^{-} \rightarrow 4 \mathrm{OH}^{-} & \text {(Eq. 1) } \\ \text { Anodic reaction } & \mathrm{Mg} \rightarrow \mathrm{Mg}^{2+}+2 \mathrm{e}^{-}\end{array}$

As indicated by Eq. 4, the main products of the corrosion reaction are hydrogen gas and insoluble magnesium hydroxide. The local conditions may also promote the formation of hydroxides of the alloying elements and hydrated oxides [26].

The main role of the coating is to hinder water and oxygen access to the $\mathrm{Mg}$ substrate and especially to slow down the corrosion rate at early stages of immersion. This is possible due to the formation of stable Si-O-metal bonds which provide good adhesion to the substrate

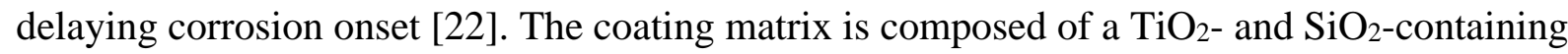
network with good barrier properties that hinders electrolyte uptake and protects the underlying metal from accelerated corrosion [44]. However, in the present case the main objective of coating is to control the corrosion process and not to prevent it completely. Consequently, a thin coating was prepared allowing the electrolyte to gradually reach the metal substrate and the corrosion processes start. The corrosion activity leads to chemical and physical degradation of the coating due to initial swelling and subsequent setting-up of corrosion products. The local alkaline environment at the metal/coating interface promotes corrosion products growth inducing mechanical stresses to the coating which results in delamination and cracking. These defects further facilitate the electrolyte access to the alloy surface and the evolution of the corrosion processes.

Taking into account that the coating thickness and morphology was reproducible for both alloys, it can be suggested that the response of the coated discs over immersion reflects the respective corrosion susceptibility of the alloy. The impedance modulus of AZ31_S showed a more stable behaviour when compared to that of ZE41_S, as observed in Fig. 4. The low frequency impedance of ZE41_S revealed a significant increase after 2 weeks suggesting the formation of a protective layer of corrosion products (see Fig. 4b). However, this protective effect was temporary and the impedance modulus decreased at a later stage. The ZE41 magnesium alloy contains rare-earth (RE) elements that may form protective RE oxides and hydroxides, decreasing the corrosion rate $[43,45]$. Then, it is reasonable to think that the formation of the corrosion layer on ZE41_S took place during first 2 weeks of immersion followed by densification from 2 to 4 weeks. After 4 weeks, nucleation and growth of defects 
in the layer due to the presence of aggressive $\mathrm{Cl}^{-}$ions allowed further corrosion and consequently a decrease of the impedance values.

In contrasts, the initial corrosion rate of AZ31_S was slower compared to ZE41_S. There may be two complementary reasons of this fact: (i) at early immersion the corrosion resistance of AZ31 alloy in SBF is higher than that of ZE41 alloy and, (ii) the coating barrier properties degrade slower on AZ31 alloy. The first rationale may be supported by the impedance values of the uncoated samples plotted in Fig. 3. The second rationale may be explained by the middle-high frequency time constant that gradually vanished over immersion (Fig. 4a). Additionally, the corrosion layer formed on AZ31_S seemed to have a quite dense and homogeneous structure (Fig. 9a). All the above mentioned, may be responsible for the rather stable behaviour of AZ31_S during immersion.

To detail the EIS results numerical fitting of the experimental data was carried out using the equivalent circuit depicted in Fig. 10a. In this model, constant phase elements (CPE) representing non-ideal capacitors were considered instead of pure capacitors. Non-ideal capacitor behaviour may be due to factors such as electrode porosity, non-uniform current distribution and variations of the coating composition [3]. The physical interpretation of the equivalent circuit is also depicted in Fig. 10 and accounts for the presence of three time constants: (i) one at high frequencies describing the barrier properties of the coating; (ii) a second one in the medium frequency range assigned to interfacial corrosion layer and, (iii) a third one at low frequencies assigned to localized corrosion activity. The $\chi^{2}$ of the regression was around $10^{-3}$.

In Fig. 10a $\mathrm{CPE}_{\text {coat }}$ accounts for the capacitive response of the coating and $\mathrm{CPE}_{\mathrm{IL}}$ for the capacitive response of the interfacial layer (IL). It is important to note that at the beginning of the experiments the interfacial layer corresponds to the $\mathrm{MgF}_{2}$ layer. However, with time this layer transforms into the corrosion products that build up underneath the coating. Likewise, $\mathrm{R}_{\text {coat }}$ and $\mathrm{R}_{\mathrm{IL}}$ account for the resistance of the solution inside the narrow coating pores and the resistance of the pores in the IL, respectively.

Fig. 10b-10e depict the evolution of the different parameters extracted from the numerical fitting. The initial values of the pore resistance $\left(R_{\text {coat }}\right)$ for both coated alloys were similar. This is reasonable since at the beginning of the immersion the coating governs the corrosion response. In this case the as-deposited coatings had similar thickness and morphology on both alloys. The barrier properties of the coating can, thus, be characterized by $\mathrm{R}_{\text {coat }}$ and $\mathrm{CPE}_{\text {coat. }}$ When $\mathrm{R}_{\text {coat }}$ decreases and $\mathrm{CPE}_{\text {coat }}$ increases the coating barrier properties deteriorate and its protective ability decreases. In Fig. 10d the initial increase in Q for CPE $(0.66<n<0.89)$ of AZ31_S may be attributed to electrolyte uptake, hereinafter the coating 
barrier properties started to degenerate. From the behaviour of the $\mathrm{Q}$ parameter for $\mathrm{CPE}_{\text {coat }}$ $(0.1<n<0.81)$ of ZE41_S it may be considered that the coating barrier properties deteriorate faster on ZE41 alloy. This is probably due to the increased corrosion activity of this alloy at early stages of immersion. Consequently, deposition and growth of the corrosion layer may occur at a faster rate inducing mechanical stresses to the coating matrix that result in structural defects, compromising the physical integrity of the coating at an earlier stage.

At the beginning of immersion RIL of AZ31_S was higher compared to RIL of ZE41_S. As depicted in Fig. 1a-1b, the $\mathrm{MgF}_{2}$ layer on AZ31 alloy had a more compact structure when compared to the same layer on ZE41 alloy. As immersion elapses, the $\mathrm{MgF}_{2}$ layer gradually dissolves and is replaced by the layer of corrosion products. Therefore, a more permeable $\mathrm{MgF}_{2}$ layer along with higher corrosion susceptibility can lead to the fast drop in RIL of ZE41_S during first 24 hours.

The impedance of a CPE is given by the following equation [3]:

$$
Z_{C P E}(\omega)=Q^{-1}(j \cdot \omega)^{-n} \quad \text { with }-1<n<1 \quad \text { (Eq. 5) }
$$

where $j$ is the imaginary number and $\omega$ is the angular frequency $(\omega=2 \pi f$, with $f$ as the frequency). The $\mathrm{Q}$ parameter of CPE becomes equal to capacitance when $n=1$ and equal to resistance when $n=0$. An inductor corresponds to $n=-1$. The $n$ values corresponding to CPEIL of AZ31_S, indicated that the interfacial layer behaviour is closer to an ideal capacitor $(0.88<n<0.95)$. This confirms that the $\mathrm{Mg}(\mathrm{OH})_{2} / \mathrm{HAP}$ layer (see Fig. 9a) formed on AZ31_S was quite stable over immersion being responsible for the passive corrosion behaviour.

The charge transfer resistance $\left(\mathrm{R}_{\mathrm{ct}}\right)$ closely followed the $\mathrm{R}_{\mathrm{IL}}$ variations. The $\mathrm{Q}$ values of the double layer capacitance $\left(\mathrm{CPE}_{\mathrm{dl}}, 0.90<n<0.98\right)$ of AZ31_S decreased from 24 hours to 1 week probably due to coating swelling. At this point the corrosion processes had already started. The precipitation/accumulation of corrosion products blocked the pores and defects in the coating through which the ions from the electrolyte are transported. The ions cannot reach the substrate and consequently the CPEdl decreased. The subsequent decline of the coating barrier properties reactivates these pathways and corrosion processes can proceed.

The wide fluctuations in $\mathrm{R}_{\mathrm{IL}}$ and CPE $\mathrm{IL}(0.62<n<0.95)$ of ZE41_S indicated that its corrosion layer structure varied over immersion (Fig. 10c and 10e). An increase in the RIL means that the IL structure becomes more compact [27]. In the same way, a decrease in the Q 
parameter for CPEIL may be attributed to thickening of the layer. The capacitance of parallel plates is expressed by the following expression [27]:

$C=\epsilon A / d$

(Eq. 6)

where $\epsilon$ is permittivity of the dielectric material between plates and $A$ and $d$ the area and separation of the parallel plates of the capacitor, respectively. Analogically, Q is equivalent to capacitive response $(C)$ and $d$ to the corrosion layer thickness. As observed in Fig. 10c and 10e, the initial increase in both $\mathrm{R}_{\mathrm{IL}}$ and Q for CPEIL of ZE41_S suggest that the corrosion layer forms from 24 hours to week $1^{\text {st }}$. After 1 week, the continuous rise in $\mathrm{R}_{\mathrm{IL}}$ and the corresponding decrease in Q for CPE $\mathrm{IL}$ may indicate densification and thickening of the IL, respectively. As depicted in Fig. 9b, large areas of the $\mathrm{Mg}(\mathrm{OH})_{2} / \mathrm{HAP}$ layer on ZE41_S were detached. These areas may expose either a new-fresh-metallic surface that reacts with the electrolyte to initiate the formation of a new fraction of the corrosion layer, or a cavitated zone in the corrosion layer that may become thicker afterwards. If this process is cyclic, it can be reflected in wide variations of the resistance and the capacitive response. Since resistance is inversely proportional to capacitance, the overall impedance response will be governed by the process with the highest Q value [33].

Lamaka et al. [22] studied the corrosion performance of ZK30 (3.0 wt\% Zn, $0.3 \mathrm{wt} \%$ $\mathrm{Zr}) \mathrm{Mg}$ alloy coated with a hybrid GPTMS:Ti coating doped with $\mathrm{Ce}^{3+}$ ions. The study demonstrated that precipitation of $\mathrm{Ce}(\mathrm{OH})_{3}$ and $\mathrm{Ce}(\mathrm{OH})_{4}$ contributed to seal the corrosion layer structure, leading to a temporary increase of its resistance. Alkalinisation at the substrate/coating interface is likely to promote the formation of rare-earth hydroxides that may contribute to the initial stability of the ZE41_S corrosion layer. The fact that these hydroxides were not detected by EDX analysis may be due to their lower content in comparison to other elements. In respect to x-ray diffraction results, the equipment used in this study may have low analytical limit and therefore patterns from precipitates in low quantity and crystal phases traces are difficult to detect. Moreover, Raman results suggested that the ILs of both AZ31_S and ZE41_S were poorly crystalline. Ascencio et al. [3] studied the influence of immersion time on the corrosion mechanisms of WE43 (4.0 wt\% Y, $3.0 \mathrm{wt} \%$ $\mathrm{RE}) \mathrm{Mg}$ alloy in modified SBF. They found that changes in the impedance response at advanced stages of immersion (120 hours) were due to rupture of the corrosion layer and lateral growth of stable pits [3]. Furthermore, from combined ART-FTIR and XRD results they demonstrated that the top-most corrosion layer was composed of an amorphous $\mathrm{Mg}(\mathrm{OH})_{2}$ and carbonated apatite mixture [3]. 
The response of $\mathrm{R}_{\mathrm{ct}}$ and Q for CPE $\mathrm{dl}(0.76<n<0.98)$ of ZE41_S showed that these parameters were governed initially by the coating properties, and thereafter by the formation and breakdown of the protective corrosion layer. After week $5^{\text {th }}$, the resistance and the capacitive response of ZE41_S stabilized. This may be due to enlarged coating delaminated areas. When delaminated areas extent and reach a large fraction of the total coated surface, the corrosion becomes almost uniform and the electrochemical response is close to that expected for the uncoated metal.

The presence of $\mathrm{Ca}$ and $\mathrm{P}$ in the corrosion products layer revealed that the $\mathrm{SBF}$ influences the nature of the corrosion products, as reported by Ascencio et al. [3]. Li et al. [31] suggested that a $\mathrm{Mg}(\mathrm{OH})_{2}$ layer provides favourable sites for hydroxyapatite nucleation via calcium immobilization on its surface. These nuclei grow spontaneously, consuming the calcium and phosphate ions from the surrounding fluid [32]. As $\mathrm{pH}$ rises, the ion strength of the electrolyte increases and hence the ionic activity inducing formation of $\mathrm{Ca}-\mathrm{P}$ nuclei and their posterior growth. The formation of the nuclei induces changes in the barrier properties of the formed interfacial $\mathrm{Mg}(\mathrm{OH})_{2}$ layer and can contribute for the observed impedance fluctuations too. Worth of notice is the fact that $\mathrm{Ca}$ and $\mathrm{P}$ were detected in higher quantities in the coated discs. This might be related to more concentrated local alkalinization in the buried areas where the coating delaminates.

Taken together, these data indicate that the coating can efficiently slow down the corrosion of the here studied Mg alloys in SBF under static conditions. However, further experiments would be required to extrapolate these results to the in vivo condition where the complexity of the biological fluids, the dynamic conditions as well as the mechanical loads acting over the materials can all together impact on their final corrosion behavior. Nevertheless, it must be pointed out that the deposition of a corrosion layer containing hydroxyapatite on the metal surface should favors bone deposition on the implant surface and consequently limit metallic ions accessibility into the body fluids. In this sense, this study contributes to the development of a route to control the corrosion activity of $\mathrm{Mg}$ alloys intended to be used as biodegradable metallic implants.

\section{Conclusions}

Thin $\mathrm{TiO}_{2}$-modified silane coatings can be used to slowly control the corrosion rate of AZ31 and ZE41 Mg alloys. The coating barrier properties degrade faster on the rare-earth containing ZE41 alloy, due to its decreased corrosion resistance at early stages of immersion. However, the build-up of a thick $\mathrm{Mg}(\mathrm{OH})_{2}$ /hydroxyapatite layer, as observed in the SEM analysis, induces wide variations on the corrosion activity as confirmed by electrochemical 
impedance results. Contrarily, the $\mathrm{Mg}(\mathrm{OH})_{2} /$ hydroxyapatite layer formed on the coated $\mathrm{AZ} 31$ alloy is thinner and shows a more stable behavior, degrading slowly over time.

In all the tested materials the results reveal the formation of calcium- and phosphateenriched corrosion products. However, the presence of the coating determines the composition of the calcium and phosphate compounds formed. The increase of the calcium to phosphate molar ratio in the coated discs can be assigned to a non-stoichiometric hydroxyapatite, as demonstrated by the Raman analysis. The presence of these compounds is an essential feature for the increased biocompatibility of these materials in bone repair applications.

\section{Acknowledgements}

The authors acknowledge the financial support of the project 2012-05-EM from the International Doctoral School in Functional Materials IDS-FunMat and the financial support by Fundação para a Ciência e Tecnologia (FCT) to CQE (UID/QUI/00100/2013). 


\section{References}

[1] F. Witte, Acta Biomater. 6 (2010) 1680-1692.

[2] M. Jamesh, S. Kumar, T.S.N. Sankara Narayanan, Corrosion Science 53 (2011) 645-654.

[3] M. Ascencio, M. Pekguleryuz, S. Omanovic, Corrosion Science 87 (2014) 489-503.

[4] W. Jin, G. Wu, H. Feng, W. Wang, X. Zhang, P.K. Chu, Corrosion Science 94 (2015) $142-155$.

[5] M.P. Staiger, A.M. Pietak, J. Huadmai, G. Dias, Biomaterials 27 (2006) 1728-1734.

[6] H.S. Brar, M.O. Platt, M. Sarntinoramont, P.I. Martin, M.V. Manuel, JOM 61 (2009) 3134.

[7] Y. Yun, Z. Dong, N. Lee, Y. Liu, D. Xue, X. Guo, J. Kuhlmann, A. Doepke, H.B. Halsall, W. Heineman, S. Sundaramurthy, M.J. Schulz, Z. Jin, V. Shanov, D. Hurd, P. Nagy, W. Li, C. Fox, Mater. Today 12 (2009) 22-32.

[8] X.-N. Gu, Y.-F. Zheng, Front. Mater. Sci. China 4 (2010) 111-115.

[9] D. Persaud-Sharma, A. McGoron, J. Biomim. Biomater. Tissue Engin. 12 (2012) 25-39.

[10] Y. Chen, Z. Xu, C. Smith, J. Sankar, Acta Biomater. 10 (2014) 4561-4573.

[11] Renlong Xin, Yuanming Luo, Ailing Zuo, Jiacheng Gao, Qing Liu, Materials letters 72 (2012) 1-4.

[12] T. Okuma, Magnesium and bone strength, Nutrition 17 (2001) 679-680.

[13] V. Kaesel, P.-T. Tai, Fr.-W. Bach, H. Haferkamp, F. Witte, H. Windhagen, Approach to control the corrosion of magnesium by alloying, in: K.U. Kainer (Ed.), Proceedings of the Sixth International Conference Magnesium Alloys and Their Applications, 2003, pp. 534.

[14] Guangling Song, Corrosion Science 49 (2007) 1696-1701.

[15] M.F. Montemor, Surface \& Coatings Technology 258 (2014) 17-37.

[16] A. Zomorodian, M.P. Garcia, T. Moura e Silva, J.C.S Fernandes, M.H. Fernandes, M.F. Montemor, Acta Biomaterialia 9 (2013) 8660-8670.

[17] A. Zomorodian, M.P. Garcia, T. Moura e Silva, J.C.S. Fernandes, M.H. Fernandes, M.F. Montemor, Materials Science and Engineering C 48 (2015) 434-443.

[18] Anawati, Hidetaka Asoh, Sachiko Ono, Surface \& Coating Technology 272 (2015) 182189.

[19] Fang Gao, Chenyang Xu, Huating Hu, Qi Wang, Yuanyang Gao, Hao Chen, Materials letters 138 (2015) 25-28.

[20] J.Y. Han, Z.T. Yu, L. Zhou, Applied Surface Science 255 (2008) 455-458. 
[21] Sangeetha Kunjukunju, Abhijit Roy, Madhumati Ramanathan, Boeun Lee, Joe E.

Candiello, Prashant N. Kumta, Acta biomaterialia 9 (2013) 8690-8703.

[22] S.V. Lamaka, G. Knörnschild, D.V. Snihirova, M.G. Taryba, M.L. Zheludkevich, M.G.S. Ferreira, Electrochimica Acta 55 (2009) 131.

[23] ISO/FDIS 23317:2007(E).

[24] H. Bakhsheshi-Rad, M.H. Idris, M.R. Abdul-Kadir, M. Daroonparvar, Trans. Nonferrous Met. Soc. China 23(2013) 699-710.

[25] R.C. Zeng, Y. Hu, S.K. Guan, H.Z. Cui, E.H. Han, Corrosion Science 86 (2014) 171182.

[26] H.E. Friedrich, B.L. Mordike. Magnesium Technology, Springer-Verlag, Berlin, Heidelberg, 2006.

[27] X. Li, Z. Weng, W. Yuan, X. Luo, H.M. Wong, X. Liu, S. Wu, K.W.K. Yeung, Y.

Zheng, P.K. Chu, Corrosion Science 102 (2016) 209-221.

[28] Yanying Zhu, Guangming Wu, Yun-Hong Zhang, Qing Zhao, Applied Surface Science 257 (2011) 6129-6137.

[29] Lafuente B, Downs R T, Yang H, Stone N (2015) The power of databases: the RRUFF project. In: Highlights in Mineralogical Crystallography, T Armbruster and R M Danisi, eds. Berlin, Germany, W. De Gruyter, pp 1-30.

[30] S. Koutsopoulos, J Biomed Mater Res 62:600-612, 2002.

[31] Zijian Li, Xunan Gu, Siquan Lou, Yufeng Zheng, Biomaterials 29 (2008) 1329-1344.

[32] T. Kokubo, Thermochimica Acta 280/281 (1996) 479490.

[33] R. Pinto, M.G.S. Ferreira, M.J. Carmezim, M.F. Montermor, Electrochimica Acta 56 (2011) 1535-1545.

[34] K.A. Yasakau, M.L. Zheludkevich, S.V. Lamaka, M.G.S. Ferreira, J. Phys. Chem. B 110 (2006) 5515.

[35] J. Vormann, Mol. Aspects Med. 24 (2003) 27.

[36] H. Zreiqat, C.R. Howlett, A. Zannettion, P. Evans, G. Schulze-Tanzil, C. Knabe, Biomed. Mater. Res. 62 (2002) 175.

[37] Ren Y, Wang H, Huang J, Zhang B, Yang K, Eng Mater 2007;342-343:601-4.

[38] Ren Y, Huang J, Zhang B, Yang K, Front Mater Sci Chin 2007;1:401-4.

[39] Shaw BA, Wolfe RC, Corrosion of magnesium and magnesium-base alloys. In: Cramer SD, Convino BS, editors. ASM handbook, vol. 13B. Corrosion of materials. Metals Park, $\mathrm{OH}$ : ASM International; 2005. p. 205-27.

[40] P. Córdoba-Torres, M. Keddam, R.P. Nogueira, Electrochim. Acta 54 (2008) 518.

[41] N.T. Kirkland, N. Birbilis, M.P. Staiger, Acta Biomaterialia 8 (2012) 925-936. 
[42] G. Baril, N. Pébère, Corros. Sci. 43 (2001) 471.

[43] J. Meng, W. Sun, Z. Tian, X. Qiu, D. Zhang, Corr. Prevention of Magnesium Alloys (2013) 38-60.

[44] S.K. Poznyak, M.L. Zheludkevich, D. Raps, F. Gammel, K.A. Yasakau, M.G.S. Ferreira, Progress in Organic Coatings 62 (2008) 226-235.

[45] A. Ulrich, N. Ott, A. Tournier-Fillon, N. Homazava, P. Schmutz, Spectrochimica Acta Part B 66 (2011) 536-545.

[46] R.C. Zeng, Y. Hu, S.K Guan, H.Z. Cui, E.H. Han, Corrosion Science 86 (2014) 171-182.

[47] F. Rosalbino, E. Angeleni, S. de Negri, A. Saccone, S. Delfino. Intermetallics 13 (2005) 55.

[48] Peixin Zhu, Yoshitake Masuda, Kunihito Koumoto, Biomaterials 25 (2004) 3915-3921. 


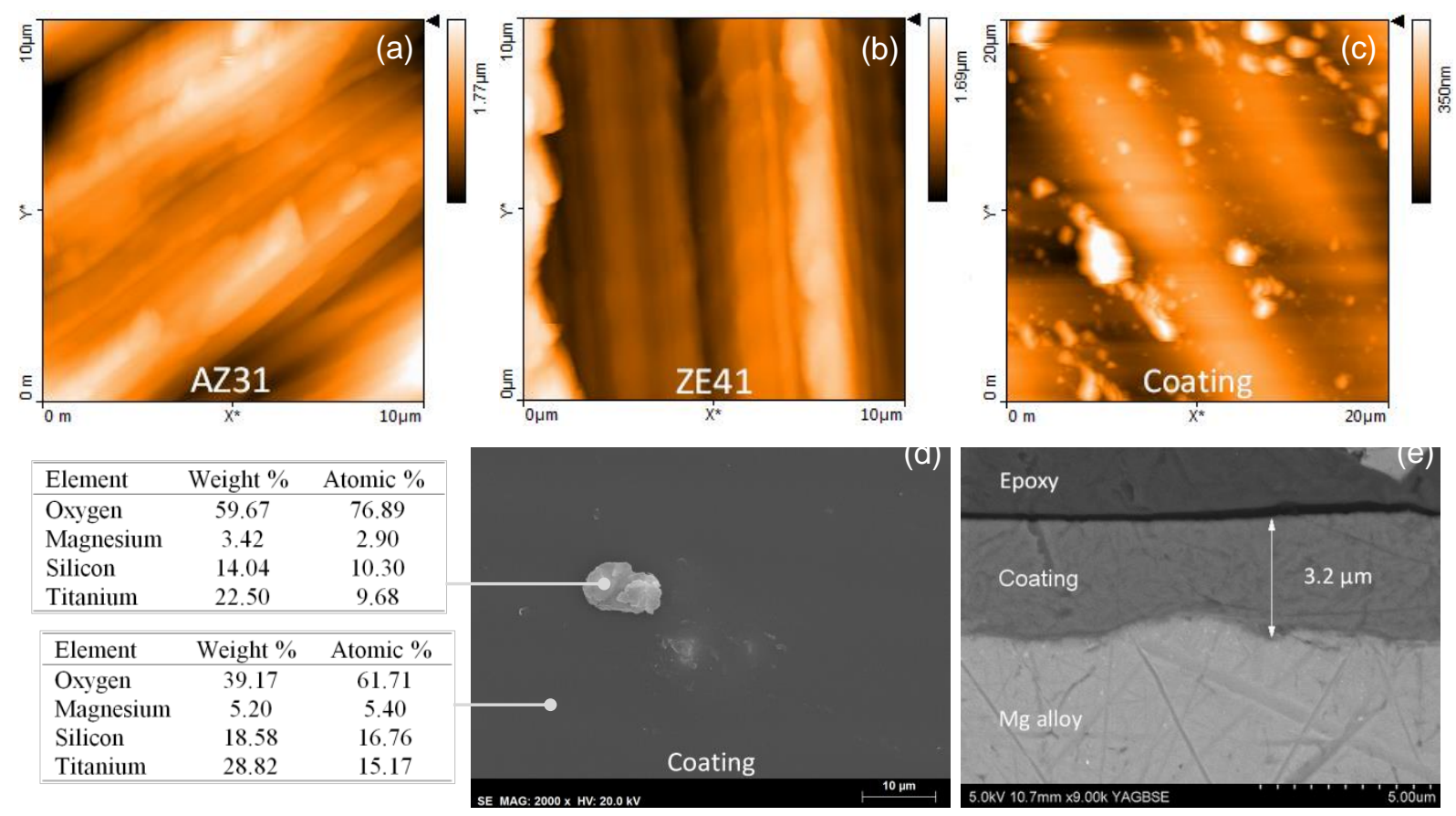

Fig. 1. Topographical AFM images of $\mathrm{MgF}_{2}$ layer on (a) AZ31 and (b) ZE41, (c) as-deposited coating. Secondary electron image of (d) as-deposited coating with EDX results and (e) backscattered electron image of coating cross section. 


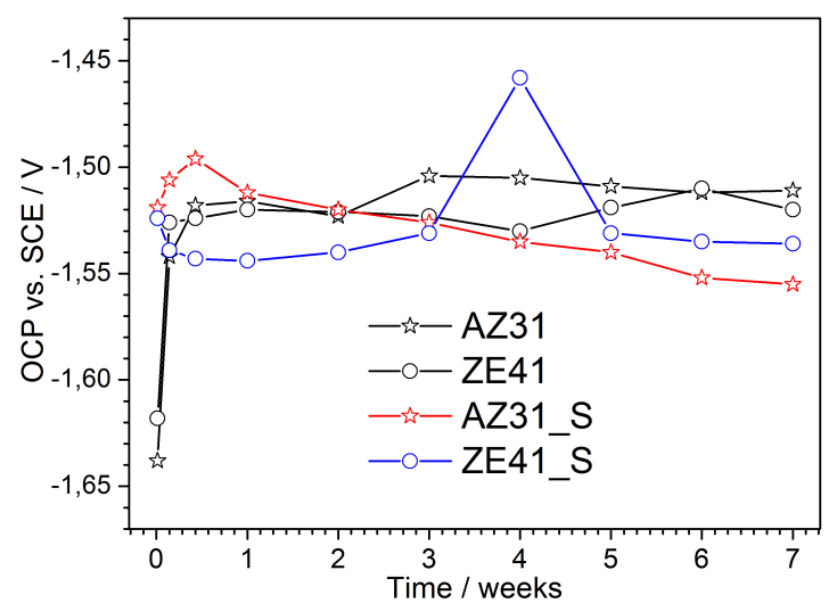

Fig. 2. OCP evolution of pre-treated and coated alloys in SBF (pH 7.4) at $37 \pm 1{ }^{\circ} \mathrm{C}$. 

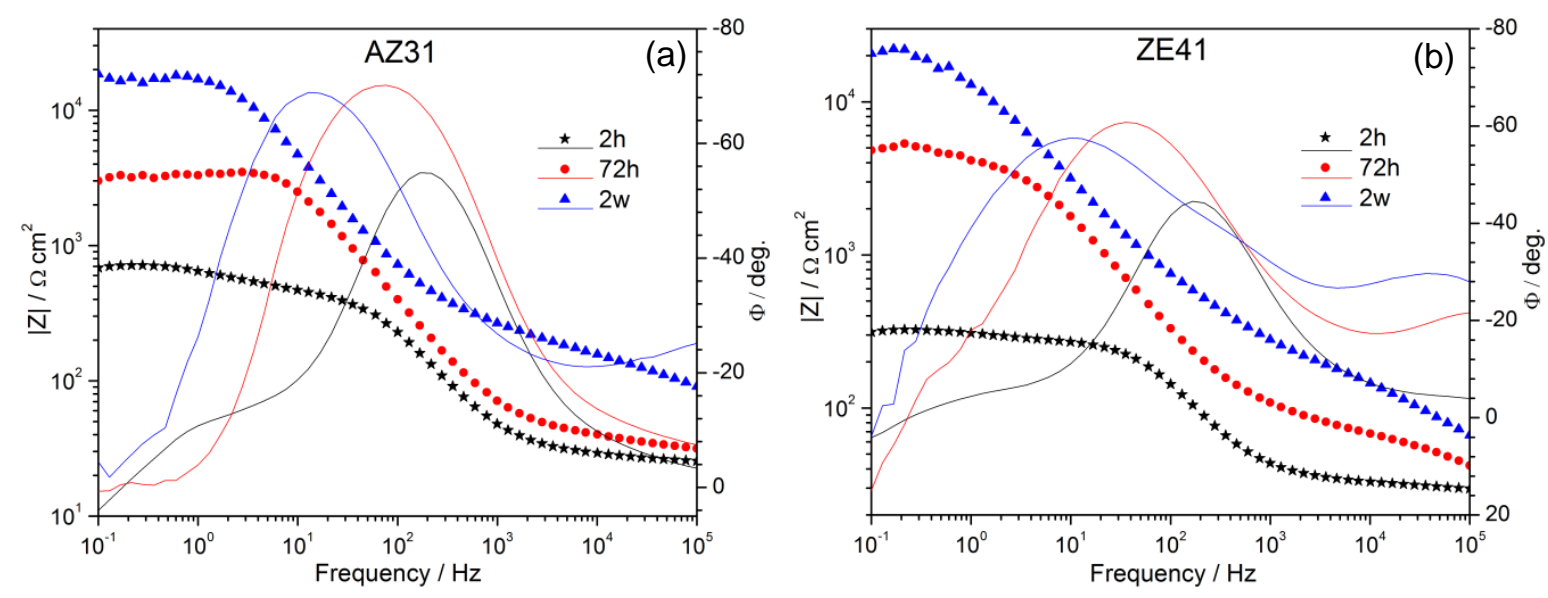

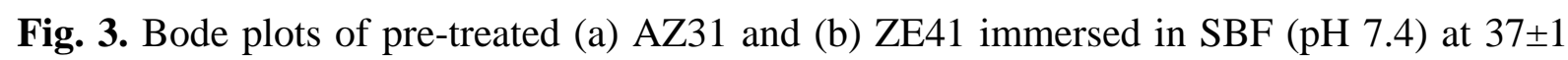
${ }^{\circ} \mathrm{C}$. Symbols are impedance values $|\mathrm{Z}|$ and lines are phase angle values $(\phi)$. 

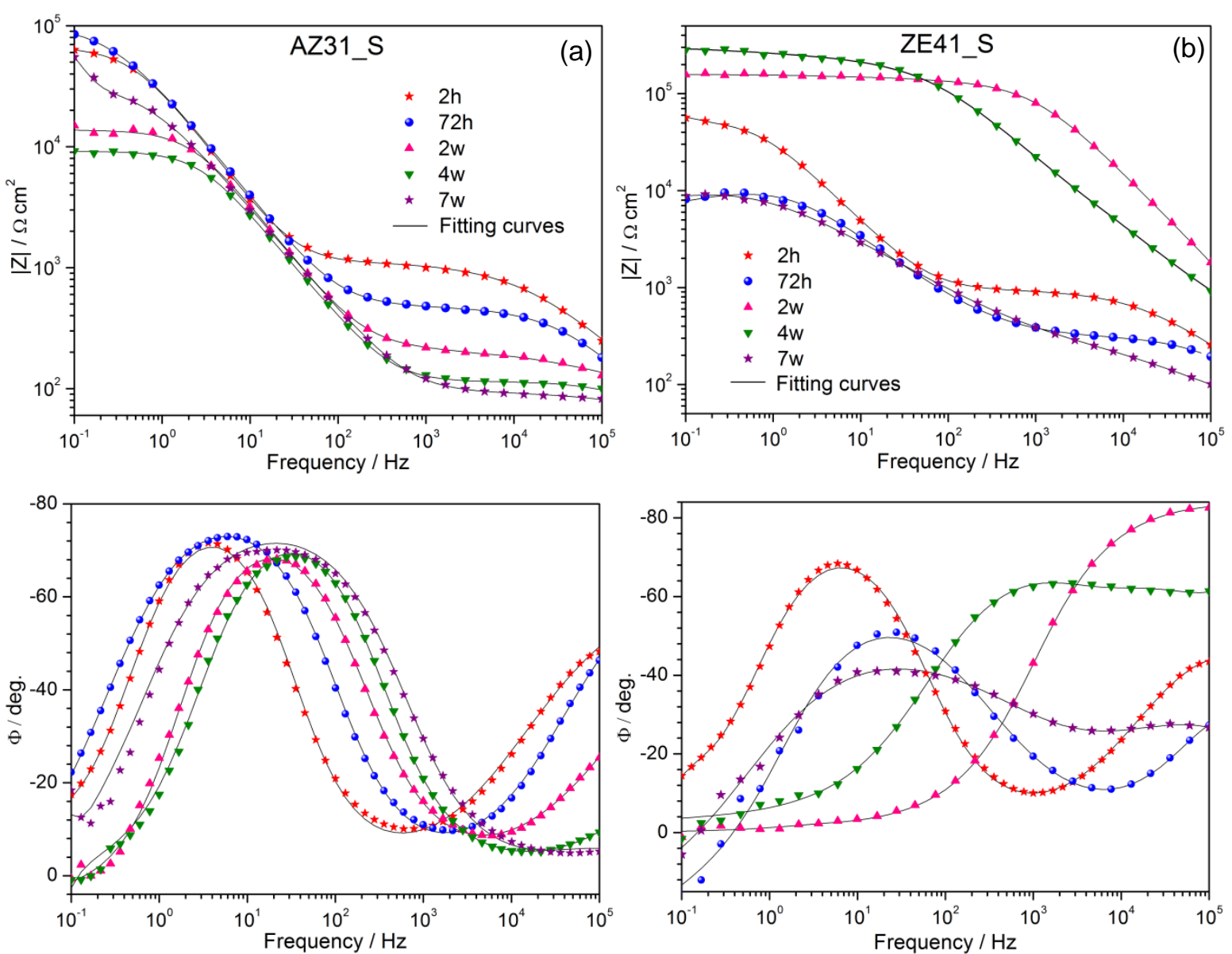

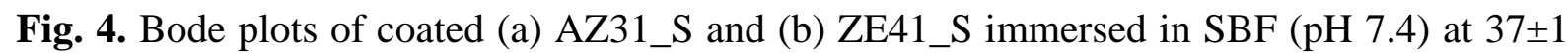
${ }^{\circ} \mathrm{C}$ for 7 weeks. 

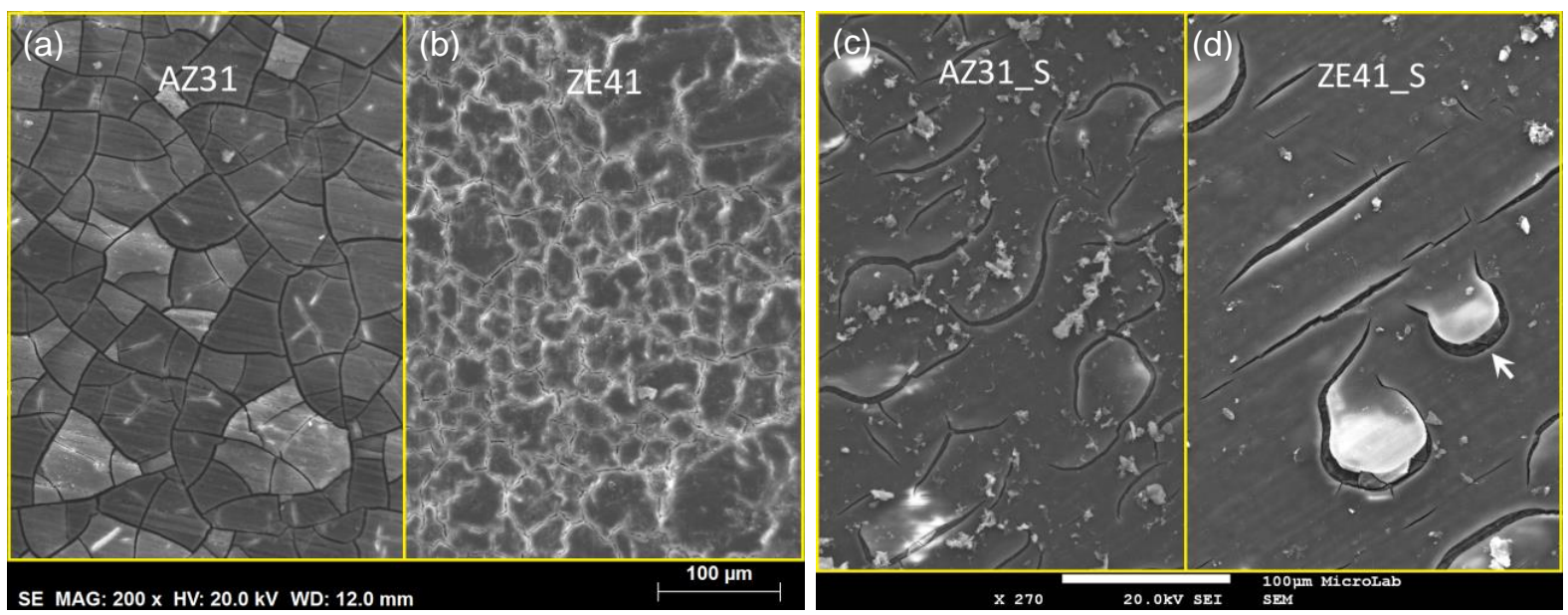

Fig. 5. Morphology of uncoated and coated discs after EIS experiments in SBF at $37 \pm 1^{\circ} \mathrm{C}$ for 7 weeks: (a) AZ31, (b) ZE41, (c) AZ31_S and (d) ZE41_S. 

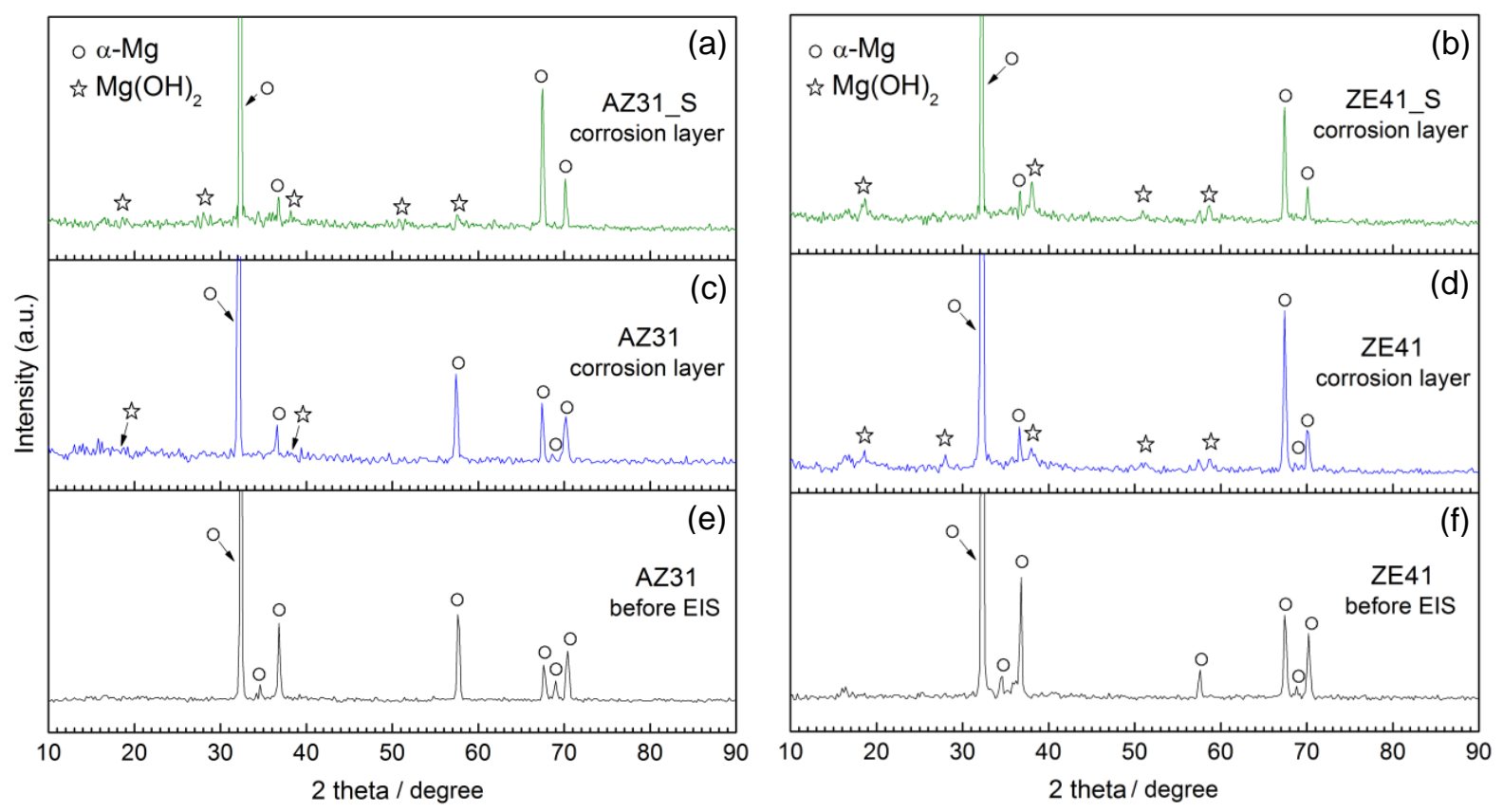

Fig. 6. XRD patterns of the corrosion layers on coated (a) AZ31_S, (b) ZE41_S and pretreated (c) AZ31, (d) ZE41. XRD patterns of pre-treated (e) AZ31 and (f) ZE41 before EIS. 

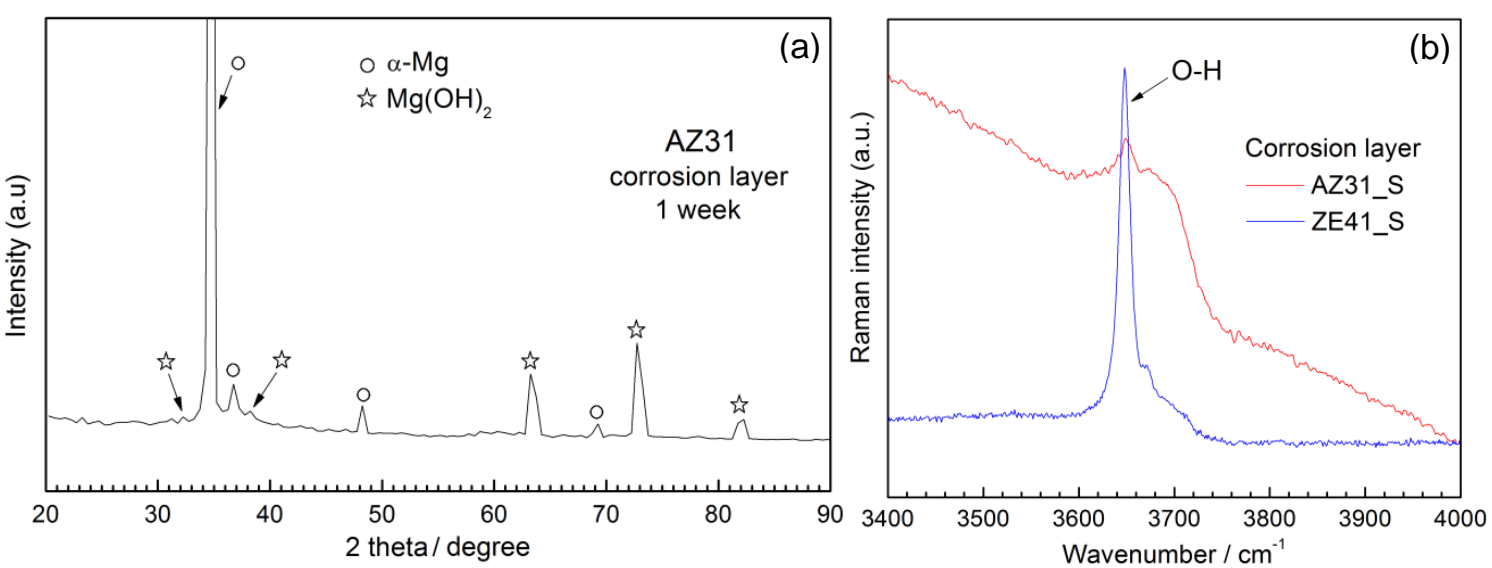

Fig. 7. (a) XRD pattern of corrosion layer on AZ31 after 1 week and (b) Raman spectra of the corrosion layers on AZ31_S and ZE41_S after 7 weeks in SBF at $37^{\circ} \mathrm{C}$. 

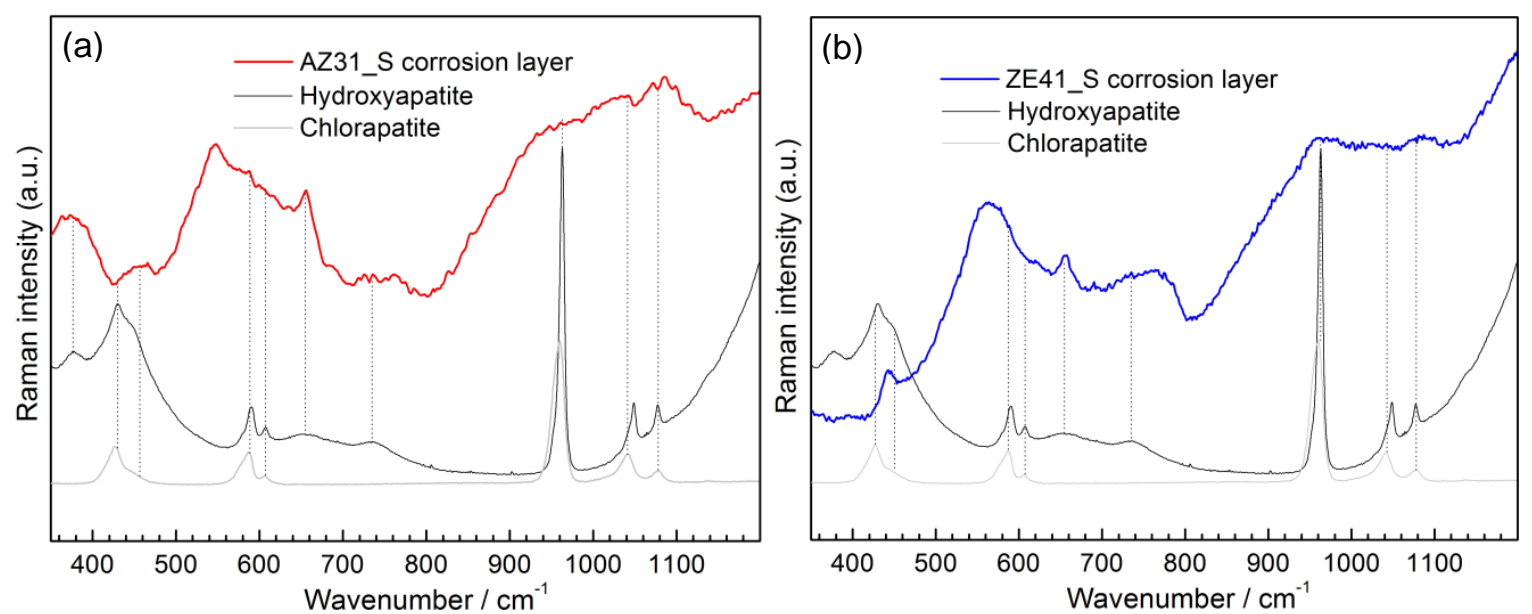

Fig. 8. Raman spectra of the corrosion layer on (a) AZ31_S and (b) ZE41_S after 7 weeks in comparison to hydroxyapatite and chlorapatite Raman spectra [29]. 

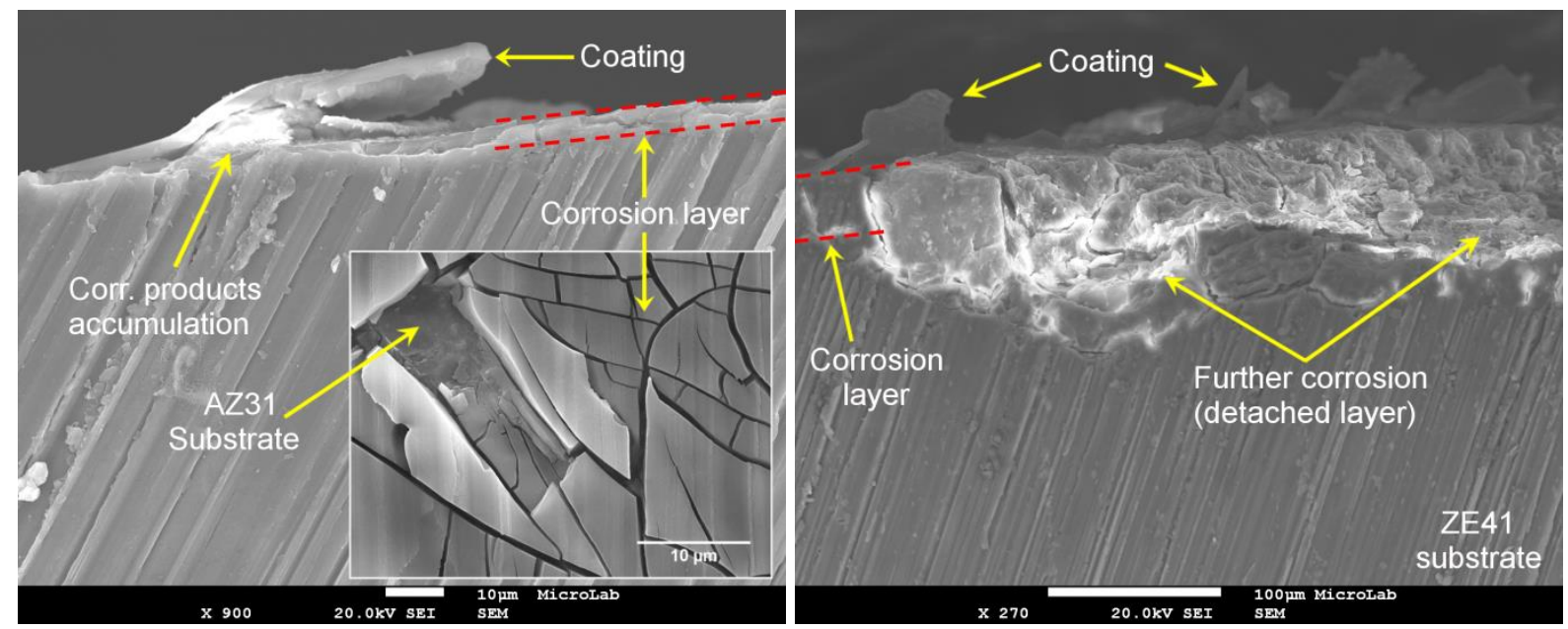

Fig. 9. Cross-sectional secondary electron images of (a) AZ31_S and (b) ZE41_S after 7 weeks in SBF at $37^{\circ} \mathrm{C}$. The inset in (a) depicts a plane-view of the AZ31_S corrosion layer after coating removal. 

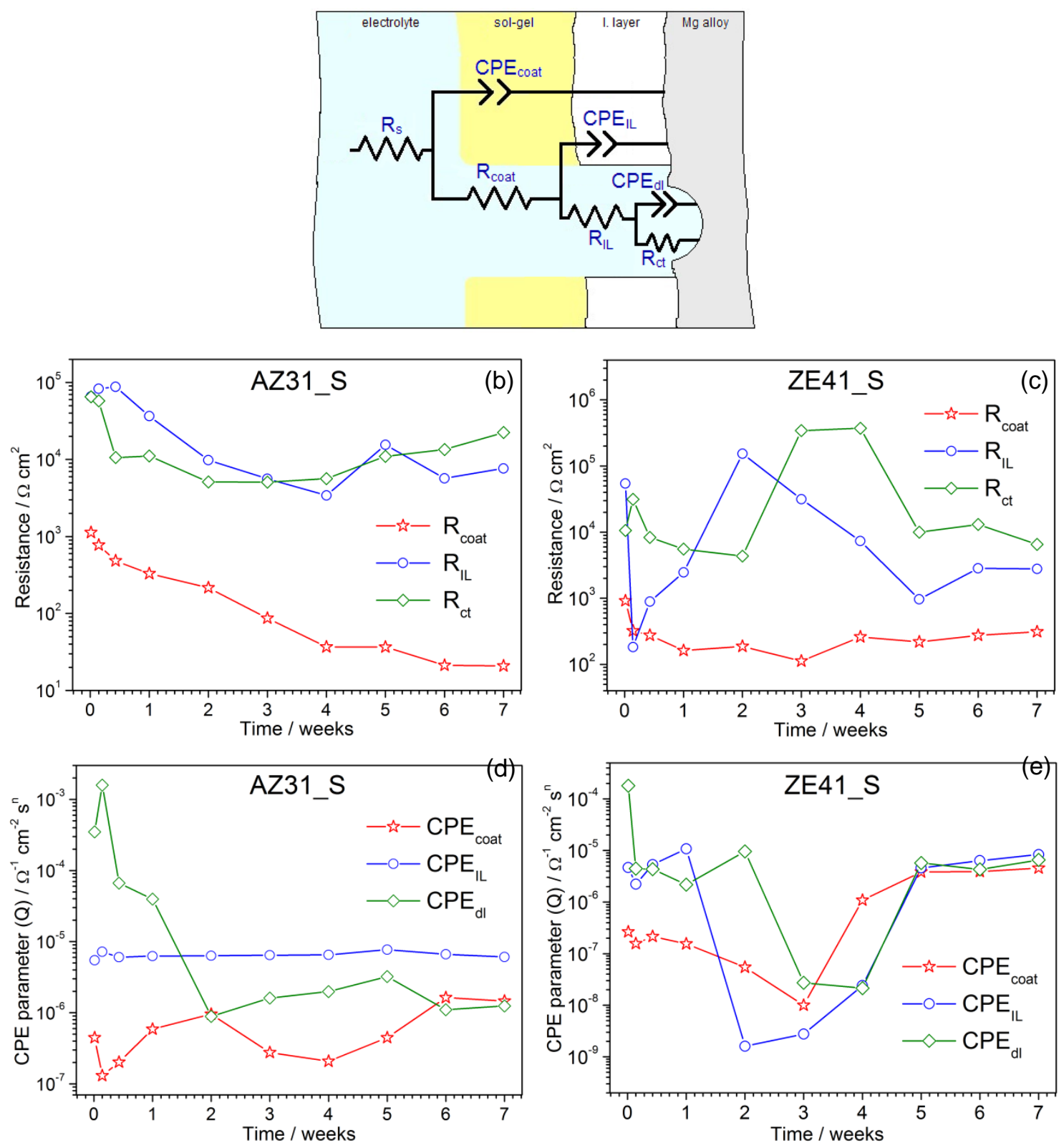

Fig. 10. (a) Equivalent circuit used to fit the EIS data. Evolution of the resistance for (a) AZ31_S and (b) ZE41_S. CPE parameter Q for (c) AZ31_S and (d) ZE41_S. 
Table 1. Chemical composition of the Mg alloys.

\begin{tabular}{llllll}
\hline Alloy & Al & Zn & RE* $^{*}$ & Zr & Mn \\
\hline AZ31 & 3 & 1 & - & - & 0.3 \\
ZE41 & - & 4.3 & 1.3 & 0.6 & - \\
\hline
\end{tabular}

* Ce, La, Nd and other rare earths 
Table 2. List of reagents required to prepare $1000 \mathrm{ml}$ of SBF (pH 7.4).

\begin{tabular}{lc}
\hline \multicolumn{1}{c}{ Reagents $^{\mathrm{a}}$} & $\mathrm{g}$ \\
\hline $\mathrm{NaCl}$ & 8.035 \\
$\mathrm{NaHCO}_{3}$ & 0.355 \\
$\mathrm{KCl}$ & 0.255 \\
$\mathrm{~K}_{2} \mathrm{HPO}_{4} \cdot 3 \mathrm{H}_{2} \mathrm{O}$ & 0.231 \\
$\mathrm{MgCl}_{2} \cdot 6 \mathrm{H}_{2} \mathrm{O}$ & 0.311 \\
$1 \mathrm{M}-\mathrm{HCl}$ & $40(\mathrm{ml})$ \\
$\mathrm{CaCl}_{2}$ & 0.292 \\
$\mathrm{Na}_{2} \mathrm{SO}_{4}$ & 0.072 \\
$\mathrm{TRIS}$ & 6.118 \\
$\left(\mathrm{CH}{ }_{2} \mathrm{OH}\right)_{3} \mathrm{CNH} 2$ & $0-5(\mathrm{ml})$ \\
$1 \mathrm{M}-\mathrm{HCl}^{\mathrm{b}}$ & \\
\hline${ }^{\mathrm{a}} \mathrm{Listed}$ in sequence of \\
dissolution \\
${ }^{\mathrm{b}} \mathrm{To}$ adjust pH 7.4
\end{tabular}


Table 3. Surface chemical composition of all tested conditions before and after EIS measured by EDX.

\begin{tabular}{|c|c|c|c|c|c|c|c|c|c|}
\hline \multicolumn{10}{|c|}{ Elemental composition, atomic $\%$} \\
\hline Before EIS & $\mathrm{O}$ & $\mathrm{Mg}$ & $\mathrm{Al}$ & & $\begin{array}{l}\text { efore } \\
\text { EIS }\end{array}$ & $\mathrm{O}$ & $\mathrm{Mg}$ & $\mathrm{Zn}$ & \\
\hline $\begin{array}{l}\text { pre-treated } \\
\text { AZ31 }\end{array}$ & 19.09 & 77.09 & 2.61 & & $\begin{array}{l}\text { treated } \\
1\end{array}$ & 15.23 & 80.62 & 2.71 & \\
\hline $\begin{array}{l}\text { Corrosion } \\
\text { layer }^{*}\end{array}$ & $\mathrm{O}$ & $\mathrm{Mg}$ & $\mathrm{Ca}$ & $\mathrm{P}$ & $\mathrm{C}$ & $\mathrm{Cl}$ & $\mathrm{Si}$ & $\mathrm{Ti}$ & $\mathrm{Ca} / \mathrm{P}$ \\
\hline AZ31 & 38.47 & 11.49 & 1.71 & 2.03 & 40.95 & 0.32 & - & - & 0.84 \\
\hline ZE41 & 45.08 & 16.22 & 1.74 & 2.26 & 33.58 & 0.73 & - & - & 0.77 \\
\hline AZ31_S & 76.00 & 15.82 & 2.82 & 1.18 & - & 2.08 & 2.09 & 0.59 & 2.39 \\
\hline ZE41_S & 71.99 & 17.08 & 3.01 & 1.47 & - & 2.21 & 2.56 & 1.89 & 2.04 \\
\hline
\end{tabular}

${ }^{*}$ After 7 weeks in SBF at $37 \pm 1^{\circ} \mathrm{C}$ 